\title{
ON MEDICINA:
}

25 a 27 de Outubro de 2021

ISBN: 978-65-81152-17-8

\section{COMPORTAMIENTO DE RIESGO PARA INFECCIONES DE TRANSMISIÓN SEXUAL EN ESTUDIANTES DE MEDICINA}

Semana Online Científica de Medicina, 1a edição, de 25/10/2021 a 27/10/2021

ISBN dos Anais: 978-65-81152-17-8

SANCHES; CARNeIRO, Patrícia ${ }^{1}$, SOUZA; SILVA, Carla Nayane ${ }^{2}$, BRUNA; VINCK, ${ }^{3}$, IVAN; BALHEJO, Erick ${ }^{4}$, RUFIN; ROdRIGUES, Marcos Dione ${ }^{5}$, TALITA; SPESSE, ${ }^{6}$, STEFANía; COHEN, 7

\section{RESUMO}

Introducción: Las ITS son un importante problema de salud de los estudiantes de Medicina. Objetivo y método: El objetivo fue evaluar el comportamiento de riesgo para Infecciones de Transmisión Sexual (ITS) en estudiantes de Medicina de la Universidad Nacional de Mar del Plata. Se diseñó un cuestionario anónimo on line que fue completado por 105 estudiantes con edades comprendidas entre 18 y 43 años. Resultados: El promedio de inicio de las relaciones sexuales fue de $16,6 \pm 2,7$ años y $23,8 \%$ señaló estar con dos o más parejas sexuales al mismo tiempo. El número de relaciones sexuales fue de aproximadamente $8,5 \pm 6,9$ veces al mes. El uso regular de preservativos se observó en el $54 \%$ de la muestra. En los que no usaban preservativos, $29,4 \%$ afirmó no tener acceso gratuito al método y un $11 \%$ utilizaba de manera habitual anticonceptivos orales (ACO) como forma de prevención de ITS. La prevalencia de las ITS fue de $9,5 \%$, siendo la más frecuente el Herpes (9 casos). Se registró también un caso de VIH. Se verificó que el $100 \%$ de los casos de ITS registrados pertenecieron al grupo de individuos que no utilizaba protección durante la relación sexual. Hubo una relación inversa entre el número de parejas y el uso de este método: $(57,4 \%$ con pareja única vs el $42,6 \%$ con múltiples parejas $(p=0,04)$ ). Entre los 77 participantes que afirmaron tener conocimiento suficiente sobre las ITS, el $38,2 \%$ no usaba preservativos de manera habitual. Conclusión: Existe desinformación con respecto al uso de diferentes anticonceptivos ya que un porcentaje de la muestra cree que todos los MAC protegen contra ITS, a pesar de que este tema ha sido estudiado en varias asignaturas desde ler año. Cabe preguntarse si para el cambio de conductas de riesgo es suficiente contar con información o si es necesario incorporar otras estrategias.

PALAVRAS-CHAVE: estudiantes de Medicina, Infecciones de Transmisión Sexual (ITS) 